\title{
Experimental analysis of a rigid rotor supported on aerodynamic foil journal bearings
}

\author{
M. Arghir ${ }^{1}$, F. Balducchi ${ }^{1}$, A. Pilavoine ${ }^{2}$ \\ ${ }^{1}$ Institut Pprime, UPR CNRS 3346, Université de Poitiers, France \\ ${ }^{2}$ ENSMA ISAE Poitiers, France
}

\begin{abstract}
Aerodynamic foil bearings are highly non linear components used or intending to be used for supporting high speed rotors $(>30 \mathrm{krpm}$ ) of low size rotating machines ( $<400 \mathrm{~kW})$. The non linear character comes from the highly deformable structure of the bearing made of thin steel sheets and from the Coulomb friction forces arising during dynamic displacements. The present work shows the non linear response of a rigid rotor supported by a pair of such bearings and entrained at $82 \mathrm{krpm}$. The measurements performed during the coast down revealed sub synchronous and asynchronous vibrations of the rotor and their multiples. A simplified theoretical model reproduces qualitatively some of these non linear characteristics.
\end{abstract}

\section{Introduction}

Aerodynamic foil bearings (AFB) represent an encouraging technology for high speed rotating rotors of small and average size [1]. These journal bearings use a very thin air film (of the order of $10 \mu \mathrm{m}$ ) as lubricant. Together with the rotor speed, the air viscosity and compressibility are the capital physical properties that explain the pressure generation in the thin air film and the lifting capacities of the bearing. The main advantages stemming from the use of air is that lubricant oil is eliminated. The overall design of the rotating machine is therefore simpler, its weight is decreased and power losses leading to component heating are lower [2]. The drawback of using air as lubricant are its low damping characteristics. Indeed, journal bearings are generally the only source of damping in rotordynamics. Oil lubricated bearings have good damping with linear characteristics that are absent or largely diminished in AFB. This can be easily understood if one takes into account that unsteady forces arising from the squeeze effect and responsible of damping are mainly proportional to viscosity. The ratio between the viscosity of air and oil is less than $10^{-3}$ and indicates that the damping provided by compressible air thin film is negligible. Aerodynamic foil bearings therefore use a compliant structure to increase damping. Several technological solutions are depicted in Figure 1 and the AFB used in the present work are shown in Figure 2. The compliant structures are made of thin Inconel foils $(\approx 100 \mu \mathrm{m})$. During dynamic loading the foils are submitted to large displacements and Coulomb friction forces arise at contact points. These contact generate damping. Due to the compressible air film, the compliant structure and the Coulomb friction, aerodynamic foil bearings are highly non-linear mechanical components. A rotor supported by AFB and loaded by a synchronous unbalance force will therefore generate strong subsynchronous and asynchronous vibrations. Such of responses were experimentally underlined in [3-9] were the rigid and flexible rotors supported AFB showed either sub-synchronous vibrations triggered by unbalance or asynchronous vibrations. Sub-synchronous vibrations have a typical signature of $0.5 \Omega$ and appear with increasing speed and unbalance.

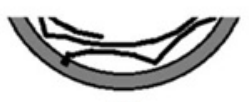

(a)

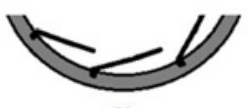

(b)

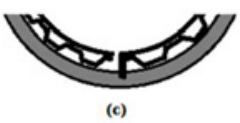

Figure 1 Technical solutions for the compliant bearing

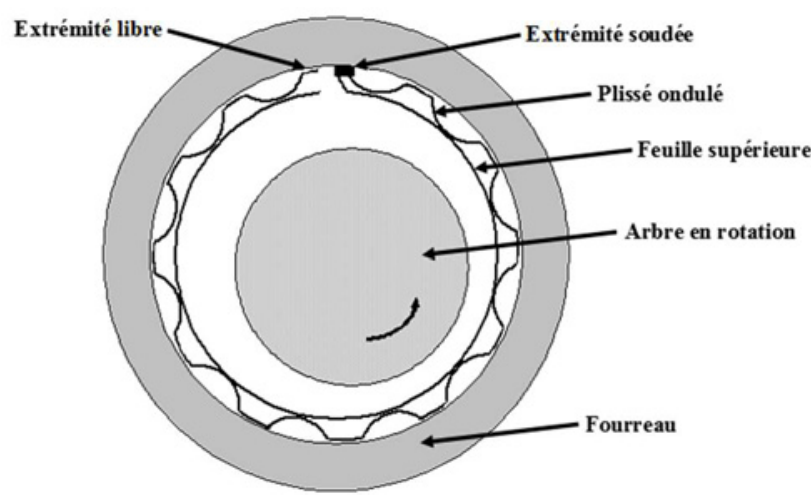

Figure 2. The aerodynamic foil bearing 


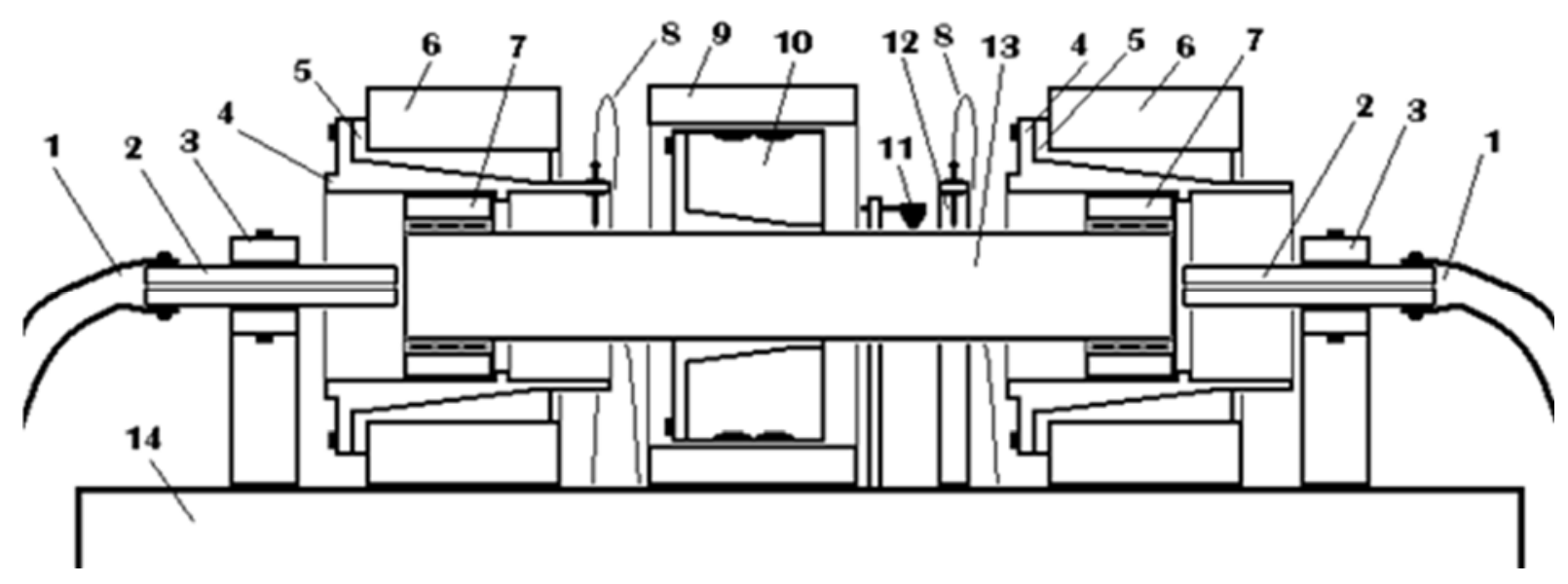

Figure 3. Test rig layout (1,2 - axial air injectors, 3 - support, 4, 5-AFB conical mounting, 6 - pedestal, 7- AFB, 8, 12 - proximity probe, 9 - turbine stator, 10 - Pelton turbine, 11 - tachometer, 13 - rotor)

They are characterized by high amplitudes that disappear with increasing rotation speed if AFB provide enough damping. Asynchronous vibrations appear at very high rotation speeds and are characterized by a constant value of the frequency corresponding to the first eigenmode of the rotor-bearing system.

Sub synchronous and asynchronous vibrations are seldom identified together during a single start-up or coast down response of the machine. Sub synchronous vibrations are easily underlined because they appear at moderate rotation speed. Asynchronous vibrations are more difficult to underline clearly because they appear at very high rotation speeds.

The present piece of work presents the experimental analysis of a rigid rotor supported on AFB exhibiting both sub synchronous and asynchronous vibrations. The relation between them is clearly underlined. The paper also presents a theoretical analysis based on a very simplified model that enlightens some of the non-linear characteristics.

\section{Experimental results}

\subsection{The test rig}

The test rig is depicted in Figure 3. It consists of a rigid rotor supported by AFB of $25 \mathrm{~mm}$ diameter at its two extremities. The disk of an air entrained Pelton turbine is mounted at the mid length of the rotor. The Pelton turbine introduces no axial loading therefore the rotor is not provided with a thrust bearing. However, two air injectors eliminate the axial translation of the rotor.

The Pelton turbine is fed by a manual valve therefore the speed of the rotor is only roughly controlled. The test rig is provided with an optical tachometer and with four proximity probes measuring the dynamic displacements close to the left hand bearing and in the vicinity of the Pelton turbine.

The frequencies of the undamped cylindrical and conical rigid modes of the rotor-bearing system are depicted in Figure 4 for values of the bearing stiffness comprised between $10^{5} \mathrm{~N} / \mathrm{m}$ and $1.35 \cdot 10^{6} \mathrm{~N} / \mathrm{m}$.

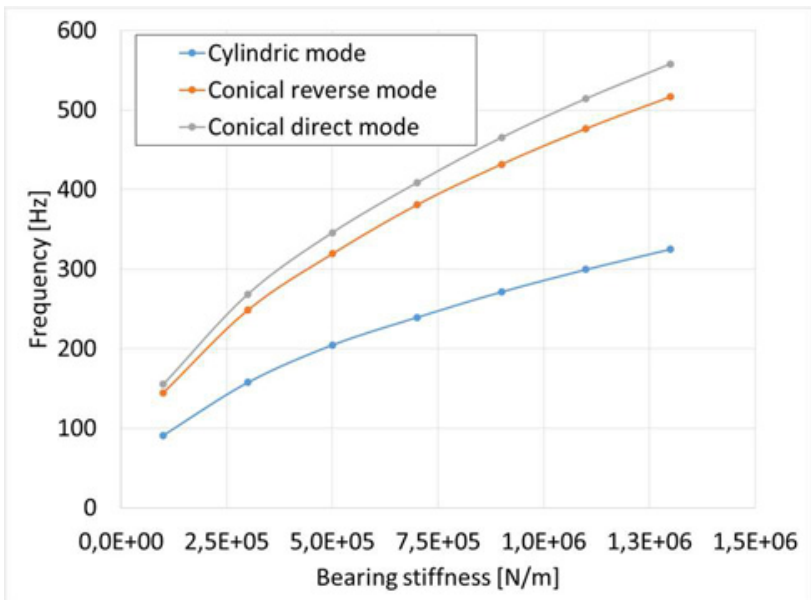

Figure 4. Undamped frequencies of the rigid modes of the rotor-bearing system

\subsection{Coast down results}

Opening the valve leads to a rapid acceleration of the rotor. Once the desired speed attained the valve is abruptly closed and the dynamic displacements of the rotor are recorded during coast down. A typical record after accelerating the rotor up to $82 \mathrm{krpm}$ is depicted in Figure 5; X1, Y1 and X2, Y2 indicate displacements measured close to the left hand bearing and close to the Pelton turbine, respectively. The rotor was loaded only by its residual unbalance. Nevertheless, the unbalance level is expected to be important because the rotor was not balanced after manufacturing or after mounting the Pelton turbine. Synchronous, sub synchronous, asynchronous vibrations and their entire multiples are clearly visible in Figure 5. The sub synchronous vibrations have a typical signature of $0.5 \Omega$ and appear for rotation frequencies lower than $300 \mathrm{~Hz}$. As suggested by Figure 4 these sub synchronous vibrations correspond to the cylindrical rigid direct mode.

For rotation speeds higher than $300 \mathrm{~Hz}$, the $0.5 \Omega \mathrm{sub}$ synchronous vibration bifurcates and then vanishes. Rotation speed regimes higher $300 \mathrm{~Hz}$ show no other sub synchronous vibration but an asynchronous vibration of $150 \mathrm{~Hz}$ and its entire multiples appears starting with 900 


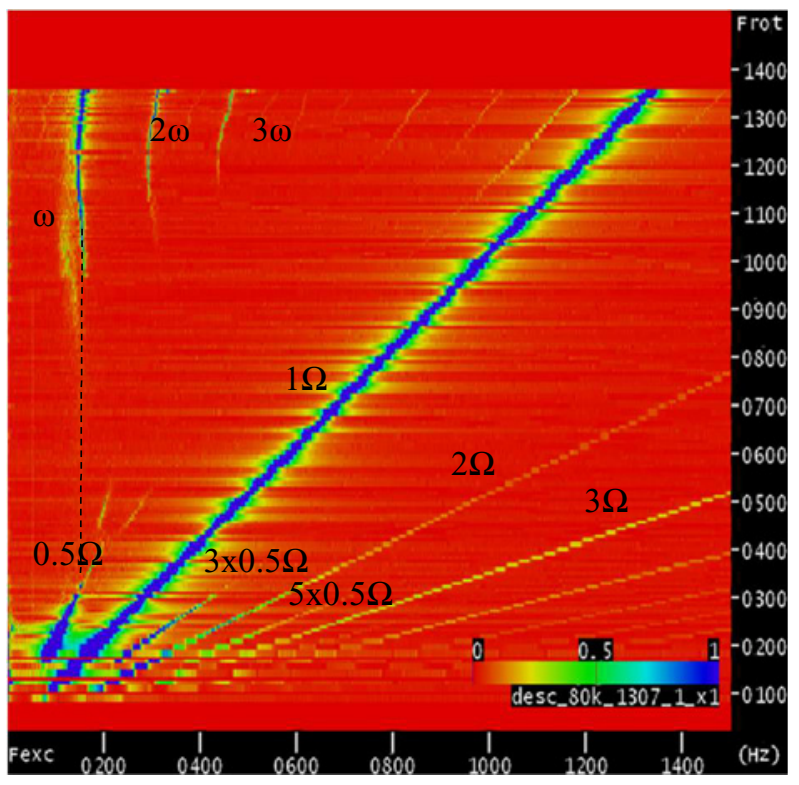

Figure 5 Waterfall plots of the rotor coast down

$\mathrm{Hz}-1000 \mathrm{~Hz}$ rotation speeds. The characteristic frequency of the asynchronous vibration corresponds to the cylindrical rigid direct mode.

\section{Theoretical results}

A theoretical model consisting of a 4 degrees of freedom rigid rotor borrowed from $[10,11]$ is employed for matching the experimental results. The equations of motion of the 4DOF rigid rotor depicted in Figure 6 are:

$M \ddot{x}=F_{X_{1}}+F_{X_{2}}+u_{b} \Omega^{2} \cos \Omega t$

$M \ddot{y}=F_{Y_{1}}+F_{Y_{2}}-M g+u_{b} \Omega^{2} \sin \Omega t$

$J_{t} \ddot{\theta}=F_{X_{1}} z_{1}+F_{X_{2}} z_{2}+J_{p} \Omega \dot{\Phi}+u_{b} \Omega^{2} z_{b} \cos \Omega t$

$J_{t} \ddot{\Phi}=-F_{Y_{1}} z_{1}-F_{Y_{2}} z_{2}-J_{p} \Omega \dot{\theta}-u_{b} \Omega^{2} z_{b} \sin \Omega t$

The bearing forces depend on the eccentricity and on the linear velocity of the rotor:

$F_{X, Y_{1,2}}=F_{X, Y}\left(x_{1,2}, y_{1,2}, \dot{x}_{1,2}, \dot{y}_{1,2}\right)$
$x_{1,2}=x+z_{1,2} \Theta, y_{1,2}=y-z_{1,2} \Phi$
$\dot{x}_{1,2}=\dot{x}+z_{1,2} \dot{\Theta}, \dot{y}_{1,2}=\dot{y}-z_{1,2} \dot{\Phi}$

The main assumption employed by this model is that the dynamic response of the rotor-bearings system is only due to the non-linear foil structure and not due to the air film.

The static force/deflection curve of the AFB was obtained by using the mounting depicted in Figure 7. The AFB was statically loaded and the deflection curve was directly measured. The results are depicted in Figure 8 and their polynomial approximation yields:

$F_{S}(r)=K_{1} r+K_{2} r^{2}+K_{3} r^{3}+K_{4} r^{4}+K_{5} r^{5}$

where $x$ or $y$ deflections were replaced by $r=\sqrt{x^{2}+y^{2}}$. This approximation is further generalized for expressing the dynamic bearing force:



Figure 6 The 4DOF rigid rotor supported on two bearings

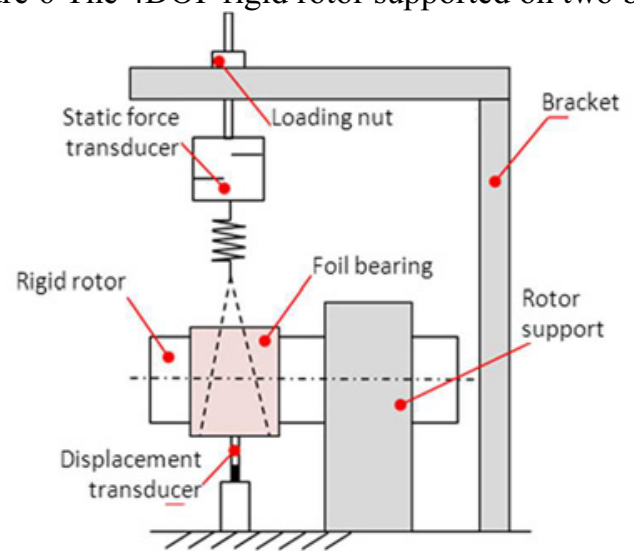

Figure 7 Mounting used for measuring the static force/deflection curve of the AFB

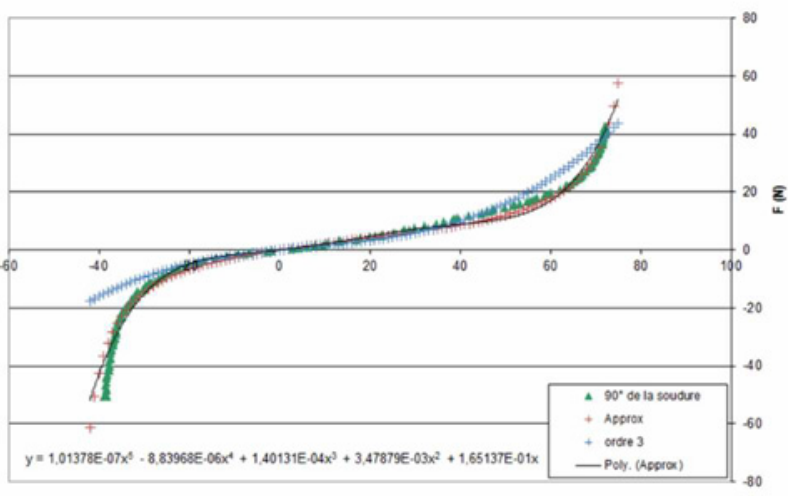
$\mathrm{d}(\mathrm{um})$

Figure 8 Experimental static force versus displacement for the AFB

$$
\begin{aligned}
& F_{X_{1,2}}=\frac{F_{S}\left(r_{1,2}\right)}{r_{1,2}}\left(x_{1,2}+\frac{\eta}{\Omega} \dot{x}_{1,2}\right) \\
& F_{Y_{1,2}}=\frac{F_{S}\left(r_{1,2}\right)}{r_{1,2}}\left(y_{1,2}+\frac{\eta}{\Omega} \dot{y}_{1,2}\right)
\end{aligned}
$$

where the damping stemming from friction between the compliant foils was expressed by using a structural (hysteretic) loss factor. These forces are injected into the equations of motion (1-4) that are numerically integrated over a large number of periods.

Numerical results obtained for a loss factor $\eta=20 \%$ are depicted in. It can be seen there is a weak similarity with the experimental results depicted in Figure 5. The theoretical results show non-linear frequency jumps but these are not correlated with measurements. The theoretical non-linear jumps occur at different rotation 
frequencies and, most notably, the sub synchronous vibrations have very different frequencies.

The explanation for this result is that the theoretical model of the bearing force is much too simple. For example, the structural damping factor is a convenient concept but it is originally defined for taking into account hysteretic damping (i.e. independent of the excitation frequency) and not damping stemming from Coulomb friction force. Even if its use would be acceptable, the definition of the dynamic stiffness used in (9) and (10) is correct only for single frequency (sinusoidal) excitations.

The previously mentioned simplifying assumptions of the air film are not unrealistic but they might be verified only at very high rotation speeds when the asymptotic behavior of the air film is fully attained.

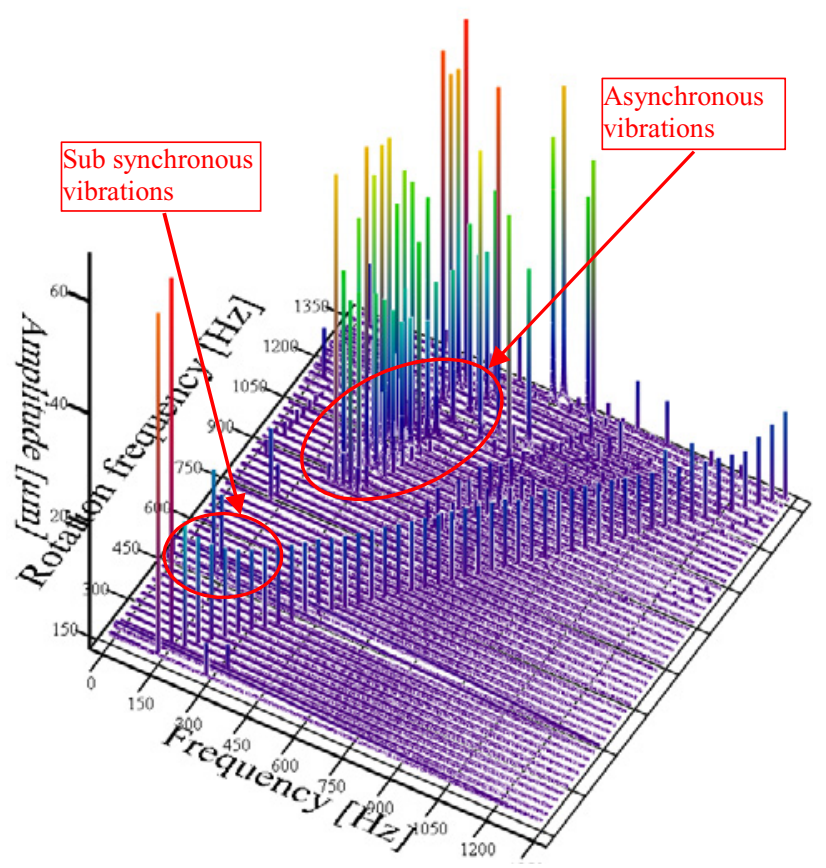

Figure 9 Theoretical waterfall plot

\section{Summary and conclusions}

The present piece of work presents the non linear response of a rigid rotor supported by a pair of air foil bearings coasting down from $82 \mathrm{krpm}$. The measurements enlightened sub synchronous and asynchronous vibrations mainly linked to the first (cylindrical) rigid mode. A very simplified theoretical model reproduces qualitatively some of these characteristics but theoretical approaches have still la long route before accurately predicting such of a complicated non linear response.

\section{References}

1. G. L. Agrawal, «Foil Air/Gas Bearing Technology An Overview» ASME paper 97-GT-347 (1997).

2. H. Heshmat, "Advancements in the performance of aeodynamic foil journal bearings: high speed and load capacity» Journal of Tribology, vol. 116, $\mathrm{n}^{\circ} \% 12$, pp. 287-295 (1994).
3. H. Heshmat, «Operation of Foil Bearing Beyond the Bending Critical Mode» ASME Journal of Tribology, vol. 122, $\mathrm{n}^{\circ} \% 11$, pp. 192-198 (2000).

4. J. F. Walton, H. Heshmat, M. J. Tomaszewski, «Testing of a small turbomachinery/turbojet size simulator rotor supported on foil bearings» GT200453647 Proceedings of 2004 ASME Turbo Expo: Power for Land, Sean and Air, Vienna, Austria (2004).

5. Y. B. Lee, T. H. Kim, C. H. Kim, N. S. Lee, D. H. Choi, «Unbalance Response of a Super-Critical Rotor Supported by Foil Bearings - Comparison with Test Results» STLE Tribology Transactions, vol. 47, $\mathrm{n}^{\circ}$ \%11, pp. 54-60 (2004).

6. Y. B. Lee, T. H. Kim, C. H. Kim, N. S. Lee, D. H. Choi, «Dynamic Characteristics of a Flexible Rotor System Supported by Viscoelastic Foil Bearings (VEFB)» Tribology International, vol. 37, pp. 679687 (2004).

7. Y. B. Lee, T. H. Kim, C. H. Kim, «Suppression of Subsynchronous Vibrations Due to Aerodynamic Response to Surge in a Two-Stage Centrifugal Compressor with Air Foil Bearings,» Tribology Transactions, vol. 46, n \%13, pp. 428-434 (2003).

8. K. Sim, Y. Lee, T. H. Kim, «Effects of Mechanical Preload and Bearing Clearance on Rotordynamic Performance of Lobed Gas Foil Bearings for Oil-Free Turbochargers» Tribology Transactions, vol. 56, $\mathrm{n}^{\circ}$ \%12, pp. 224-235 (2013).

9. L. San Andrés, D. Rubio, T. H. Kim, «Rotordynamic Performance of a Rotor Supported on Bump Type Foil Gas Bearings: Experiments and Predictions» Journal of Engineering for Gas Turbines and Power, vol. 129, $\mathrm{n}^{\circ} \% 13$, pp. 850-857 (2007).

10. L. San Andrès, T. H. Kim, «Issues on Instability and Forced Nonlinearity in Gas Foil Bearing Supported Rotors» AIAA/ASME/SAE/ASEE Joint Propulsion Conference \& Exhibit, AIAA2007-5094 (2007).

11. L. San Andrés, T. H. Kim, «Forced nonlinear response of gas foil bearing supported rotors» Tribology International, vol. 41, pp. 704-715 (2008).

\section{Nomenclature}

$\begin{array}{ll}F & \text { force }[\mathrm{N}] \\ f & \text { frequency }[\mathrm{Hz}] \\ f_{r} & \text { rotation frequency [Hz] } \\ J_{t}, J_{p} & \text { transversal and polar moment of inertia }\left[\mathrm{kgm}^{2}\right] \\ K_{i} & \text { stiffness coefficients used in eq. (8) } \\ M & \text { mass [kg] } \\ r & \text { radial distance }[\mathrm{m}] \\ t & \text { time [s] } \\ u_{b} & \text { unbalance }[\mathrm{kgm}] \\ x, y, z & \text { global coordinate system } \\ \Omega & \text { rotation speed [rad } / \mathrm{s}] \\ \theta, \Phi & \text { rotation angles [rad] } \\ \eta & \text { structural loss factor } \\ \text { Subscripts } & \\ 1,2 & \text { bearing } 1 \text { and } 2\end{array}$

